\title{
Bone Collagen Turnover in Idiopathic Scoliosis Estimated from Total Hydroxyproline Excretion
}

\author{
P. A. ZORAB, STEPHANIE CLARK, Y. COTREL, and AILIE HARRISON \\ From the Institute of Diseases of the Chest, London, and L'Institut Calot, Berck-Plage, France
}

\begin{abstract}
Zorab, P. A., Clark, S., Cotrel, Y., and Harrison, A. (1971). Archives of Disease in Childhood, 46, 828. Bone collagen turnover in idiopathic scoliosis estimated from total hydroxyproline excretion. The turnover of bone collagen is reflected by the 24-hour excretion of urinary total hydroxyproline. In idiopathic scoliosis there is an increase above normal in the turnover of bone collagen throughout adolescence. Spinal immobilization in plaster-of-Paris, spinal traction, and spinal fusion are all accompanied by increases in the turnover of bone collagen. It is suggested that estimation of the urinary total hydroxyproline excretion is useful in monitoring spinal changes during the treatment of children with idiopathic scoliosis and may reflect otherwise unsuspected changes in the bone collagen.
\end{abstract}

Scoliosis seldom occurs except in childhood. Its development is closely related to spinal growth, worsening most rapidly at times of rapid growth and seldom altering after bone maturity.

It is not easy to study the relation between growth and scoliosis. Wide variations in what constitutes 'normal' growth and the lack of techniques for measuring changes in the vertebral column make any such study difficult. Radiography, though useful, is not sufficient by itself, for the abnormalities that occur in idiopathic scoliosis are not only those visible on a spinal $x$-ray. In an earlier study (Zorab, Harrison, and Harrison, 1968, unpublished) we concluded that the lack of vertical growth in idiopathic scoliosis was wholly due to deformity of the vertebral column, because, in the small groups studied, there was not any associated deficiency of limb growth. Duval-Beaupère (1971) reached a similar conclusion. Using tibial length as an index we found no difference in the annual growth rate among children with idiopathic scoliosis and that of normal schoolchildren of similar age. The use of physical methods to compare the growth of scoliotic with normal children, however, is neither easy nor very accurate, and this led us to seek other methods.

Collagen in its most active form is known to be contained in bone (Neuberger, Perrone, and Slack, 1951; Neuberger and Slack, 1953). This is certainly true of rats and seems to be so in humans.

Received 7 May 1971.
The collagen turnover which accompanies skeletal change is reflected by urinary excretion of total hydroxyproline (THP) (Smiley and Ziff, 1964); Sjoerdsma et al., 1965). This turnover is high, e.g. in conditions such as Paget's disease of bone and in rheumatoid arthritis (Smiley and Ziff, 1964). It is also higher in normal children than in normal adults (Anderson, Bannister, and Tomlinson, 1965). At first sight THP excretion levels may seem to be related to a child's age but this is not entirely so (Zorab, 1969). It is, in fact, related much more closely to the rate of growth, i.e. to growth velocity and thus reaches a peak during the adolescence of every child (Jasin et al., 1962; Zorab et al., 1970).

Taking the urinary total hydroxyproline excretion rate as an index of the turnover of bone collagen, we now show how this varies during different forms of treatment of idiopathic scoliosis.

\section{Method}

The 24-hour urinary THP excretion of 135 girls and 33 boys with idiopathic scoliosis, all of whom were under orthopaedic treatment in France, was compared with 371 normal girls and 310 normal boys from English boarding schools. The method of collection from the normal children has been described elsewhere (Zorab, 1969). The French and English children were both given a collagen-free diet for the duration of every collection. None was included who had been subjected to an orthopaedic operation within the previous three months. To ensure completeness, the urine collections from the children in France were supervised by the 
nursing staff at L'Institut Calot who took great trouble to ensure that the collections were complete. The French samples were analysed on the day the urine collection ended, using the same method of testing as for the normal specimens (Prockop and Udenfriend, 1960). All the biochemical work in both countries was carried out by one of us (S.C.) and similar 'spot' checks used on both occasions to ensure accuracy.

Using similar methods, a study was made of the effect of orthopaedic treatment on bone collagen turnover in 129 French children selected as follows:

(a) 50 girls with idiopathic scoliosis receiving physiotherapy only.

(b) 46 girls treated by spinal immobilization in plasterof-Paris (POP) for up to 2 months.

(c) 33 girls similarly treated by spinal immobilization in plaster-of-Paris for over 2 and up to 10 months.

All these groups were of comparable age with the normals.

We conducted two further studies on the following:

(a) 11 girls under continuous spinal traction by the method of Cotrel (Cotrel and d'Amore, 1968) for $2 \frac{1}{2}$ to 3 weeks. THP levels were measured one week before and twice weekly during traction and mean levels were calculated.

(b) 3 boys and 16 girls who had received spinal fusion. The volume, THP, and creatinine level of these were estimated just before and weekly for 3 months after operation. If all 3 were low, the specimen was considered incomplete and the result not included.

\section{Results}

The results are expressed as the mean 24-hour urinary excretion of total hydroxyproline. This is shown for each year of age in normal and scoliotic boys and girls (Fig. 1 and 2).

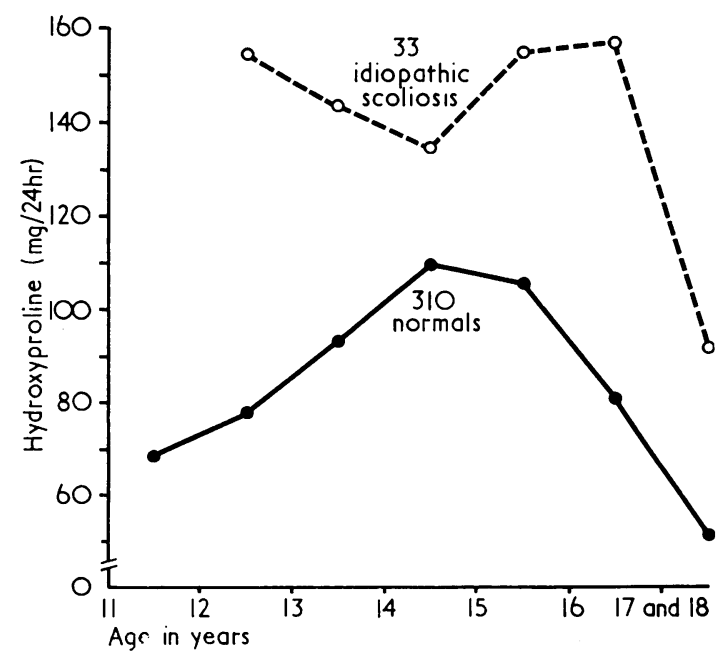

FIG. 1.-Mean urinary THP excretion in boys.

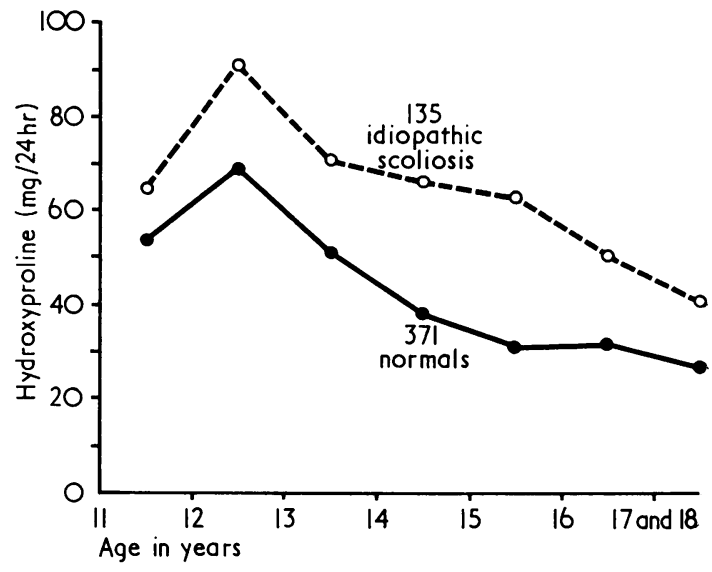

FIG. 2.-Mean urinary THP excretion in girls.

The results given in Table I show that among scoliotic children of all the ages studied and in both sexes there is a marked and continued increase above normal of THP levels. There is a highly significant statistical difference $(P>0.001)$ between the results from normal children and those from scoliotic girls of 14 to 18 years and scoliotic boys of 12 and 16. The difference is still significant $(P>0.01)$ between the results from normal and scoliotic girls of 12 years and boys of 17 years. It is just significant $(P>0.05)$ for 13-year-old girls and 15-year-old boys. There was no statistical significance in results for the youngest group of scoliotic girls (11 years) or boys (13 and 14 years). The total number of scoliotic boys in the study is small and hence the conclusions less definite than in the study of scoliotic girls.

From the results of those under spinal immobilization in plaster-of-Paris, it will be seen (Fig. 3) that there is a considerable and persistent increase in the mean THP excretion level in girls thus immobilized for 2 to 10 months. The effect is less obvious among those immobilized for a shorter period (under 2 months). But even so the levels are higher than in those children who have not been immobilized and especially those who are normal.

The effect of spinal traction on bone collagen turnover is well seen in Fig. 4. This shows that the mean THP level is increased by about half after 1 week of traction. By the end of treatment lasting up to 3 weeks, the THP had fallen to the mean pretraction level.

Spinal fusion causes a more profound and prolonged rise in collagen turnover. It will be seen (Fig. 5) that in the two weeks after spinal fusion the mean THP level is sharply raised. It then 
TABLE I

Total Hydroxyproline Excretion (mg/24 hr)

\begin{tabular}{|c|c|c|c|c|c|c|c|c|c|c|}
\hline \multirow{2}{*}{$\begin{array}{l}\text { Age } \\
(\mathbf{y r})\end{array}$} & \multicolumn{4}{|c|}{ Normal } & \multicolumn{4}{|c|}{ Idiopathic Scoliosis } & \multicolumn{2}{|c|}{$\begin{array}{l}\text { Differences Between Means } \\
\text { of Normals and Scoliotics }\end{array}$} \\
\hline & Freq. & Mean & SD & SE & Freq. & Mean & SD & SE & 't' & Significance \\
\hline $\begin{array}{l}\text { Boys } \\
11- \\
12- \\
13- \\
14- \\
15- \\
16- \\
17 \text { and } 18 \\
\text { Girls } \\
11- \\
12- \\
13- \\
14- \\
15- \\
16- \\
17 \text { and } 18\end{array}$ & $\begin{array}{l}52 \\
51 \\
48 \\
44 \\
46 \\
34 \\
35\end{array}$ & $\begin{array}{r}68 \cdot 6 \\
78 \cdot 0 \\
93 \cdot 2 \\
110 \cdot 0 \\
106 \cdot 4 \\
81 \cdot 1 \\
55 \cdot 1\end{array}$ & $\begin{array}{l}32 \cdot 48 \\
29 \cdot 37 \\
43 \cdot 85 \\
48 \cdot 03 \\
41 \cdot 62 \\
32 \cdot 01 \\
24 \cdot 02\end{array}$ & $\begin{array}{l}4 \cdot 50 \\
4 \cdot 11 \\
6 \cdot 33 \\
7 \cdot 24 \\
6 \cdot 14 \\
5 \cdot 49 \\
4 \cdot 06\end{array}$ & $\begin{array}{l}14 \\
18 \\
20 \\
34 \\
17 \\
10 \\
22\end{array}$ & $\begin{array}{r}69 \cdot 0 \\
154 \cdot 7 \\
144 \cdot 7 \\
134 \cdot 9 \\
155 \cdot 2 \\
157 \cdot 7 \\
92 \cdot 3 \\
\\
64 \cdot 9 \\
91 \cdot 2 \\
70 \cdot 9 \\
66 \cdot 8 \\
62 \cdot 9 \\
50 \cdot 8 \\
41 \cdot 6\end{array}$ & $\begin{array}{r}0 \cdot 00 \\
87 \cdot 49 \\
88 \cdot 64 \\
85 \cdot 15 \\
70 \cdot 89 \\
62 \cdot 61 \\
54 \cdot 88 \\
\\
\\
9 \cdot 84 \\
30 \cdot 84 \\
35 \cdot 42 \\
24 \cdot 02 \\
26 \cdot 01 \\
17 \cdot 06 \\
18 \cdot 71\end{array}$ & $\begin{array}{r}0 \cdot 00 \\
43 \cdot 74 \\
51 \cdot 17 \\
30 \cdot 11 \\
28 \cdot 94 \\
25 \cdot 56 \\
22 \cdot 40\end{array}$ & $\begin{array}{l}-\overline{4} \cdot 18 \\
-1 \cdot 86 \\
-1 \cdot 18 \\
-2 \cdot 48 \\
-4 \cdot 61 \\
-2 \cdot 82 \\
\\
-1 \cdot 35 \\
-2 \cdot 67 \\
-2 \cdot 62 \\
-6 \cdot 64 \\
-6 \cdot 56 \\
-4 \cdot 01 \\
-3 \cdot 77\end{array}$ & 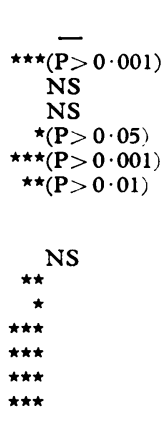 \\
\hline
\end{tabular}

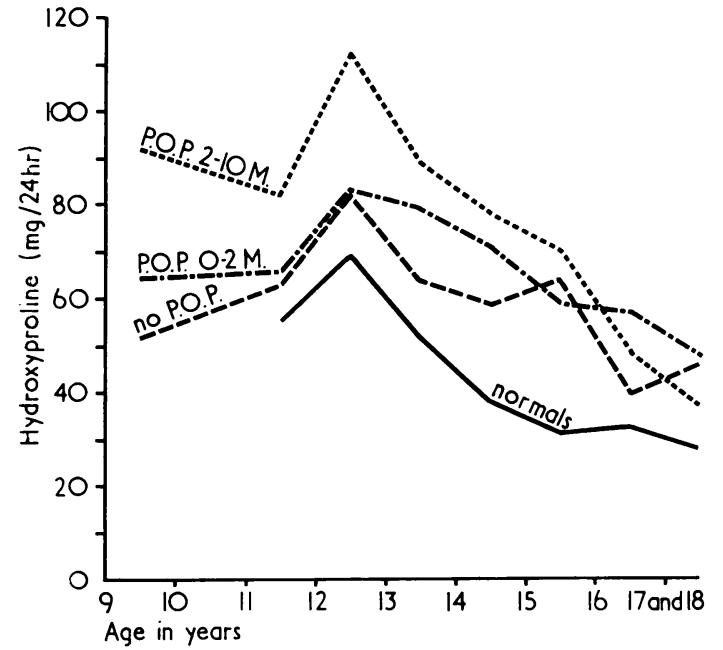

Fig. 3.-Idiopathic scoliosis: effect of spinal immobilization by plaster-of-Paris (POP) on THP excretion (means) in 137 girls.

falls gradually to the preoperative level by about the twelfth week.

\section{Discussion}

The most striking feature of our results is the persistent increase in the mean total hydroxyproline excretion in scoliotic boys and girls of 11 to 18 years. This indicates that their bone collagen turnover rate is considerably higher than normal. In our study we excluded all children who had been subjected to spinal fusion. The only exception to this was those in the special study of the effect on
THP of this operation. We included, however, children undergoing other forms of 'conservative' orthopaedic treatment. The raised excretion levels seen in Fig. 1 and 2 therefore reflect some process, other than that due to operative trauma.

The reason for the increase in the turnover of bone collagen is not obvious. It may be a consequence of the body's continued attempt to correct spinal curvature whereby the muscular pull leads to remodelling of the bony vertebral column. Or it may, though only in part, be an effect of treatment such as physiotherapy or plaster-of-Paris immobilization on the vertebral column of scoliotic children.

An earlier investigation, of girls with all types of

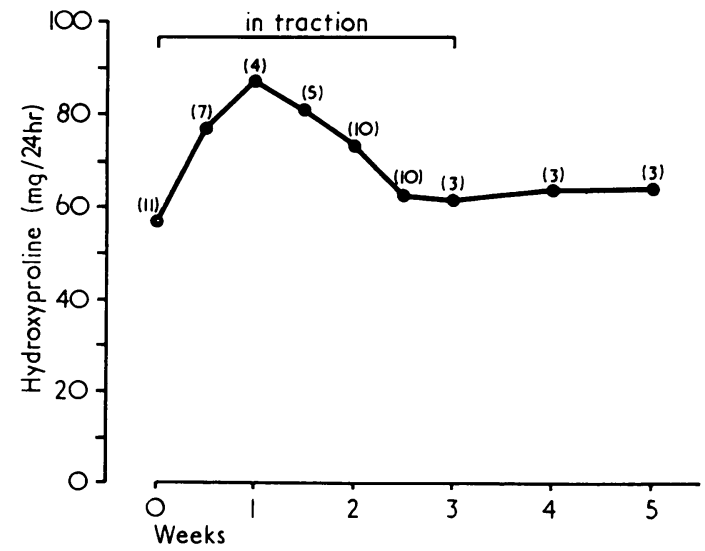

FIG. 4.-Idiopathic scoliosis: effect of spinal traction on THP excretion (means) in 11 girls. Figures in parentheses indicate number in group. 
TABLE II

Effect of Plaster Jackets (POP) on THP Excretion (mg/24 hr) in Idiopathic Scoliotic Girls

\begin{tabular}{|c|c|c|c|c|c|c|c|c|c|}
\hline \multirow{3}{*}{$\begin{array}{l}\text { Age } \\
(y \mathbf{y})\end{array}$} & \multirow{2}{*}{\multicolumn{3}{|c|}{ Not in Plaster Jacket }} & \multicolumn{6}{|c|}{ In Plaster Jacket } \\
\hline & & & & \multicolumn{3}{|c|}{$0-2$ months } & \multicolumn{3}{|c|}{ 2-10 months } \\
\hline & Freq. & Mean & Range & Freq. & Mean & Range & Freq. & Mean & Range \\
\hline $\begin{array}{l}9- \\
10- \\
11- \\
12- \\
13- \\
14- \\
15- \\
16- \\
17 \text { and } 18\end{array}$ & $\begin{array}{r}2 \\
1 \\
7 \\
6 \\
5 \\
17 \\
7 \\
3 \\
5\end{array}$ & $\begin{array}{l}51 \cdot 5 \\
86 \cdot 0 \\
62 \cdot 6 \\
82 \cdot 3 \\
63 \cdot 3 \\
58 \cdot 6 \\
64 \cdot 0 \\
39 \cdot 3 \\
45 \cdot 2\end{array}$ & $\begin{array}{l}50 \cdot 0 \text { and } 53 \cdot 0 \\
\text { 49.0-82.0 } \\
59 \cdot 0-107 \cdot 0 \\
42 \cdot 0-92 \cdot 0 \\
32 \cdot 0-103 \cdot 0 \\
41 \cdot 0-89 \cdot 0 \\
26 \cdot 0-48 \cdot 0 \\
25 \cdot 0-83 \cdot 0\end{array}$ & $\begin{array}{r}3 \\
6 \\
6 \\
6 \\
11 \\
4 \\
5 \\
8\end{array}$ & $\begin{array}{l}64 \cdot 3 \\
65 \cdot 7 \\
82 \cdot 5 \\
78 \cdot 3 \\
71 \cdot 0 \\
58 \cdot 8 \\
56 \cdot 6 \\
48 \cdot 0\end{array}$ & $\begin{array}{l}49 \cdot 0-87 \cdot 0 \\
52 \cdot 0-73 \cdot 0 \\
68 \cdot 0-95 \cdot 0 \\
46 \cdot 0-108 \cdot 0 \\
58 \cdot 0-87 \cdot 0 \\
24 \cdot 0-107 \cdot 0 \\
45 \cdot 0-72 \cdot 0 \\
32 \cdot 0-59 \cdot 0\end{array}$ & $\begin{array}{l}3 \\
1 \\
4 \\
8 \\
8 \\
6 \\
3 \\
3\end{array}$ & $\begin{array}{r}91 \cdot 7 \\
82 \cdot 0 \\
111 \cdot 5 \\
89 \cdot 4 \\
77 \cdot 8 \\
69 \cdot 5 \\
49 \cdot 0 \\
37 \cdot 0\end{array}$ & $\begin{array}{c}66 \cdot 0-106 \cdot 0 \\
\text { - } \\
98 \cdot 0-124 \cdot 0 \\
35 \cdot 0-158 \cdot 0 \\
35 \cdot 0-116 \cdot 0 \\
40 \cdot 0-102 \cdot 0 \\
47 \cdot 0-50 \cdot 0 \\
26 \cdot 0-47 \cdot 0\end{array}$ \\
\hline
\end{tabular}

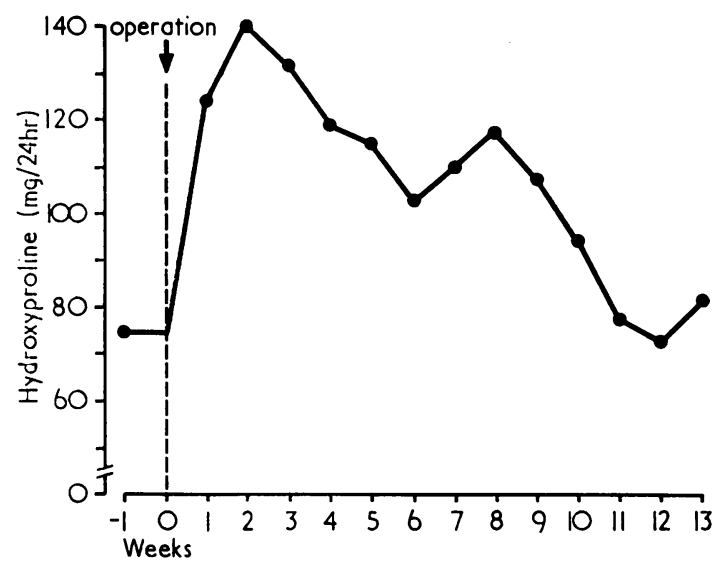

Fig. 5.-Idiopathic scoliosis: effect of spinal fusion on THP excretion (means) in 16 girls and 3 boys.

scoliosis, into the effect of spinal immobilization by plaster-of-Paris jackets on THP excretion showed no marked differences between those in and those not in plaster-of-Paris (Zorab, 1968). The present study has been confined to those with 'idiopathic' scoliosis. The THP excretion again suggests that there is very little difference between the turnover of bone collagen in those not in plaster-of-Paris and in those treated in it for up to 2 months. Longer periods of spinal immobilization, however do produce obvious rises in THP levels.

This suggests that spinal immobilization in plaster, prolonged for more than 2 months, leads to a considerable increase in the turnover of bony collagen. This may be the result of remodelling of the vertebrae.

The serial effect of spinal traction on 11 girls with idiopathic scoliosis, seen in Fig. 4, suggests that during the first week of spinal traction there is a considerable increase in the turnover of body collagen. This may be due to the effect of initial 'stretching'. The decreased THP level in the second week may be due to the traction having a smaller effect. The maximum effect of treatment may have been achieved in the first week. After traction has ended the effect ceases altogether.

After spinal fusion the disturbance of bone collagen is seen to last for about three months. It is worth noting that in the cases studied only bone grafts were inserted. Harrington instrumentation was not used. The high postoperative THP level must be due to sharply increased bone activity during this period of repair and remodelling.

None of the foregoing explains why the THP excretion level in scoliotic children treated by physiotherapy alone remains high. This increase may be due to abnormal mechanical stresses on the spine of patients who are ambulant. It may be the result of the particularly effective and vigorous physiotherapy given at L'Institut Calot which increases further the amount of this stress. An interesting suggestion made by Brenton (1971) is that the increase may sometimes be caused by an inborn error of metabolism. No doubt there are other possible explanations.

We accept that it would have been preferable for the comparison to have been made between scoliotic and normal children drawn from the same country. This was not possible. However, there is every reason to think that the results of these two groups can be satisfactorily compared. Diet was collagen free and was strictly supervised. The same technician carried out the urinary estimations on both groups. The technique on both occasions was identical. Furthermore, it has been shown that growth rates for normal French children are the same as for normal English children (Tanner, 1968). The possibility that 'idiopathic' scoliosis in France is due to a different cause from that in 
other countries is too improbable to merit serious consideration.

The causation of scoliosis remains unknown. No attempt made so far has succeeded in showing why spinal curvature may become progressively more severe during the years of growth. Though paralytic and congenital scoliosis may seem so different from 'idiopathic' scoliosis there is no obvious process at work in the 'idiopathic' types causing the curvature to become progressively more severe. In paralytic scoliosis (following poliomyelitis) the muscle wasting makes the progression of scoliosis relatively easy to understand.

The apparent relation between the age at which scoliosis frequently worsens and the 'growth velocity' at that age suggests that the rate of growth of the vertebral column and its surrounding structures are worth careful study. $X$-rays, however, tend largely to reveal structural events several weeks or months after they have occurred. Urinary total hydroxyproline excretion levels reveal current biochemical changes and may thus provide a useful additional method of monitoring structural change.

The causation of idiopathic scoliosis is unlikely to be revealed by the use of any single method, but THP excretion studies at least make possible the study of bone collagen turnover. If a similar technique should become available for the study of muscle development any imbalance between growth rates of the bony vertebral column and surrounding muscles could then be shown. The development of such a technique is surely the next step in the study of idiopathic scoliosis.

We thank Mr. C. W. Manning for his constant encouragement; Monsieur A. Debeaumont for laboratory facilities, for his supervision, and his continual interest; and the Nursing and Administrative Staff of L'Institut
Calot for organizing the urine collections and for arranging dietary control. The work was supported by The Brompton Hospital Research Fund, The Action for the Crippled Child Fund, The Sir Halley Stewart Trust, and the Variety Club of Great Britain, to all of whom we are very grateful.

\section{REFERENCES}

Anderson, J., Bannister, D. W., and Tomlinson, R. W. S. (1965) Total urinary hydroxyproline excretion in normal human subjects. Clinical Science, 29, 583.

Brenton, D. P. (1971). Proceedings of a 3rd Symposium on Scoliosis and Growth, p. 114 . Livingstone, Edinburgh.

Cotrel, Y., and d'Amore, M. (1968). Spinal traction in scoliosis. In Proceedings of a 2nd Symposium on Scoliosis: Causation, p. 37. Ed. by P. A. Zorab. Livingstone, Edinburgh.

Duval-Beaupère, G. (1971). Proceedings of a 3rd Symposium on Scoliosis and Growth, p. 63. Livingstone, Edinburgh.

Jasin, H. E., Fink, C. W., Wise, W., and Ziff, M. (1962). Relationship between urinary hydroxyproline and growth. Fournal of Clinical Investigation, 41, 1928.

Neuberger, A., Perrone, J. C., and Slack, H. G. B. (1951). The relative metabolic inertia of tendon collagen in the rat Biochemical fournal, 49, 199.

Neuberger, A., and Slack, H. G. B. (1953). The metabolism of collagen from liver, bone, skin and tendon in the normal rat. Biochemical fournal, 53, 47

Prockop, D. J., and Udenfriend, S. (1960). A specific method for the analysis of hydroxyproline in tissues and urine. Analytical Biochemistry, 1, 228.

Sjoerdsma, A., Udenfriend, S., Keiser, H., and LeRoy, E. C. (1965). Hydroxyproline and collagen metabolism. Annals of Internal Medicine, 63, 672.

Smiley, J. D., and Ziff, M. (1964). Urinary hydroxyproline excretion and growth. Physiological Reviews, 44, 30.

Tanner, J. M. (1968). A comparison of rates of physical growth of French and English children. Proceedings du centre Internationale de l'Enfance, Brussels.

Zorab, P. A. (1968). Total hydroxyproline excretion in scoliosis. In Proceedings of a 2nd Symposium on Scoliosis: Causation, p. 55. Ed. by P. A. Zorab. Livingstone, Edinburgh.

Zorab, P. A. (1969). Normal creatinine and hydroxyproline excretion in young persons. Lancet, 2, 1164.

Zorab, P. A., Clark, S., Harrison, A., and Seel, J. R. (1970) Hydroxyproline excretion and height velocity in adolescent boys. Archives of Disease in Childhood, 45, 763.

Zorab, P. A., Harrison, A., and Harrision, W. J. (1968). Tibial length in scoliotic children. (Unpublished.)

Correspondence to Dr. P. A. Zorab, Institute of Diseases of the Chest, London S.W.3. 